\title{
Quantification of rotator cuff tear geometry: the repair ratio as a guide for surgical repair in crescent and $U$-shaped tears
}

\author{
Utku Kandemir $\cdot$ Robert B. Allaire $\cdot$ \\ Richard E. Debski · Thay Q. Lee · Patrick J. McMahon
}

Received: 20 January 2009 / Published online: 24 March 2009

(C) The Author(s) 2009. This article is published with open access at Springerlink.com

\begin{abstract}
Introduction Surgical repair of symptomatic, retracted rotator cuff tears unresponsive to non-operative treatments requires closure of the tear without undue tension and reattaching the torn tendon to its former insertion site. In this study, the length of the torn tendon edge was hypothesized to be longer than the length of the humeral insertion site. The objective of this study was to quantify the discrepancy in length of the torn tendon edge and the length of the avulsed humeral insertion site.

Materials and methods Full thickness, rotator cuff tears that were found in twelve fresh frozen cadaver shoulders was studied. The length of the torn tendon edge, the length of the avulsed humeral insertion site and the retraction were measured using digital calipers.

Results Each tear involved the supraspinatus and the infraspinatus was additionally torn in six. The size of the tear was medium in eight and large in four. The length of the torn tendon edge was always longer than the length of the avulsed
\end{abstract}

U. Kandemir $(\square)$

Department of Orthopaedic Surgery,

University of California San Francisco,

1001 Potrero Av. Room 3A36, San Francisco, CA 94110, USA

e-mail: kandemiru@orthosurg.ucsf.edu

R. B. Allaire · P. J. McMahon

Department of Orthopaedic Surgery,

University of Pittsburgh, Pittsburgh, USA

R. E. Debski

Department of Bioengineering,

University of Pittsburgh, Pittsburgh, USA

T. Q. Lee

Orthopaedic Biomechanics Laboratory,

Long Beach VAMC, University of California, Irvine, USA humeral insertion site. Retraction was $29.9 \pm 9.3 \mathrm{~mm}$ (range $21-48 \mathrm{~mm}$ ). The repair ratio, defined as the ratio of length of torn tendon edge to the length of avulsed humeral insertion site, was $2.6 \pm 0.4$ (range 2.1-3.5).

Conclusion As only the length of the torn tendon edge equal to the length of the avulsed humeral insertion site can be repaired to bone, a repair ratio more than one precludes a simple repair and an additional repair technique such as margin convergence would be necessary for the remaining unapproximated torn tendon edge in rotator cuff tears. Repair ratio may aid in selection of the surgical repair technique of these rotator cuff tears.

Keywords Rotator cuff tear $\cdot$ Repair $\cdot$ Retraction . Insertion

\section{Introduction}

Tears of the rotator cuff tendons are one of the most common causes of shoulder pain and disability [1]. Yet treatment is complicated by variability in shoulder symptoms. For example, not all tears are associated with pain, weakness and loss of shoulder range of motion [2-4]. For those that are symptomatic, the goals of treatment are pain relief and improvement in function. Non-operative care includes non-steroid anti-inflammatory drugs, shoulder muscle rehabilitation and steroid injections. Surgical intervention is indicated for those that fail these treatments or are unable to elevate the shoulder against gravity [5]. While less invasive techniques have become common in recent years [6], the basic premise of surgical repair remains the same; closure of the tear without undue tension and reattachment of the torn tendon to its former insertion site on the humerus $[7,8]$. 
Classification of rotator cuff tears has aided surgical treatment. Tears have been classified based on many factors including size [9-11], shape [12-14], thickness [14], tendon involvement [15], etiology [16], duration of symptoms [17], and ability of the tear to be approximated to bone [18]. Yet reports of surgical treatment most commonly classified the rotator cuff tears by only the two factors of size and tendon involvement [19-33].

Rotator cuff tears with retraction of the torn tendon edge away from the avulsed humeral insertion site are often the most difficult to repair. Retraction of the tendon results in the length of the torn tendon edge being longer than the length of the avulsed humeral insertion site. This is implicit in the shape of rotator cuff tear with retraction, such as trapezoidal and U-shaped tears [12-14], that often require mobilization of the rotator cuff tendons and muscles. Outcome was better if such tears were repaired [7, 34-36] rather than debrided $[37,38]$ or reconstructed with fascia [39], allograft [7, 40], synthetic material [41], or other portions of the rotator cuff $[9,42]$. Yet retraction is qualitative, changing with shoulder position. The purpose of this study was to quantify the discrepancy in length of the torn tendon edge and the length of the avulsed humeral insertion site as a novel factor to aid in selection of the surgical repair technique.

\section{Materials and methods}

Forty-two fresh frozen cadaveric shoulders were dissected of the deltoid muscle exposing the rotator cuff. Twelve shoulders (mean age $79.3 \pm 9.9$ years) had a full thickness rotator cuff tear and were used for study. Seven were male and five were female. The tendons of the rotator cuff were defined by marking the borders of the muscles and tendons of the subscapularis, supraspinatus, infraspinatus and teres minor with India ink. The humerus was positioned in the scapular plane, in neutral rotation (intertubercular groove aligned with anterolateral edge of acromion), and parallel to the medial border of scapula simulating position of the arm being at the side of the body.

The geometry of the rotator cuff tear was measured with a 2-0 Ethibond suture (polyester fiber, Ethicon Inc., New Jersey, USA) and digital calipers (Absolute Digimatic, Mitutoyo Corp, Japan). The suture was meticulously positioned along the site to be measured. The limits of the site were marked with hemostat clamps on the suture. The distance between the clamps was then measured with the calipers (accuracy of $0.1 \mathrm{~mm}$ ). The length along the torn tendon(s) edge, the length of the avulsed humeral insertion site (at the articular margin), and the greatest distance from the torn tendon edge to the avulsed humeral insertion site (at the articular margin), retraction, were measured (Fig. 1). The tendons involved in the tear were recorded.

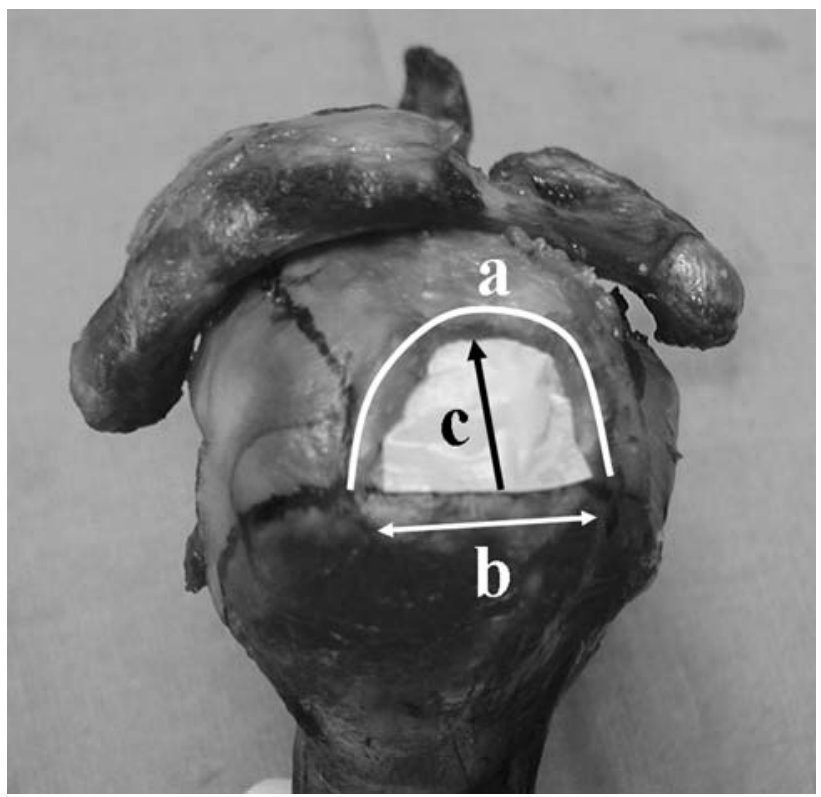

Fig. $1 a$ Length of torn tendon edge, $b$ size of the avulsed humeral insertion, $c$ distance of retraction

Each tear was then classified according to the length of the avulsed humeral insertion site as small, (less than $1 \mathrm{~cm}$ ), medium $(1-3 \mathrm{~cm})$, large $(3-5 \mathrm{~cm})$ or, massive (greater than $5 \mathrm{~cm}$ ) [10]. Tears were also classified by the tendon involvement as stage 1A if partial thickness, stage 1B if full thickness isolated to supraspinatus, stage 2 if both supraspinatus and infraspinatus tendons were involved, Stage 3 if the supraspinatus, infraspinatus and subscapularis were involved, and stage 4 if rotator cuff arthropathy had developed [15].

A paired $t$ test (two-tailed) was used to compare the length along the torn tendon edge and the length of the avulsed humeral insertion site. Pearson's test (two-tailed) was used to determine if a correlation existed between the length of torn tendon edge $(a)$ and distance of retraction $(c)$. Statistical analysis was done with the SPSS software program (version 10.0, SPSS Inc., Chicago, IL, USA).

\section{Results}

Repeated measurements (10 times) performed on one specimen were within $1.0 \mathrm{~mm}$. The length of the torn tendon edge was $74.8 \pm 23.7 \mathrm{~mm}$ (range $42-115 \mathrm{~mm}$ ) (mean \pm $\mathrm{SD})$. The length of the avulsed humeral insertion site was $29.5 \pm 9.2 \mathrm{~mm}$ (range 17-44 mm). Retraction from the torn tendon edge to the avulsed humeral insertion site was $29.9 \pm 9.3 \mathrm{~mm}$ (range $21-48 \mathrm{~mm}$ ). Eight tears were medium and four were large size. Six of the tears were stage 1B, and six stage 2 according to classification of Harryman and coworkers (Table 1) [15]. The length of the torn tendon edge was significantly greater than the length of the 
Table 1 The geometric measurements and classification of rotator cuff tears

\begin{tabular}{lllllll}
\hline Shoulder number & $a(\mathrm{~mm})$ & $b(\mathrm{~mm})$ & $c(\mathrm{~mm})$ & $a / b$ & Stage & Size \\
\hline 1 & 91 & 44 & 31 & 2.1 & 2 & Large \\
2 & 115 & 44 & 48 & 2.6 & 2 & Large \\
3 & 96 & 27 & 38 & 3.5 & 2 & Medium \\
4 & 108 & 42 & 43 & 2.6 & $1 \mathrm{~B}$ & Large \\
5 & 85 & 33 & 34 & 2.6 & $1 \mathrm{~B}$ & Large \\
6 & 68 & 26 & 28 & 2.6 & $1 \mathrm{~B}$ & Medium \\
7 & 61 & 21 & 28 & 2.9 & $1 \mathrm{~B}$ & Medium \\
8 & 42 & 17 & 18 & 2.5 & $1 \mathrm{~B}$ & Medium \\
9 & 50 & 22 & 21 & 2.3 & $1 \mathrm{~B}$ & Medium \\
10 & 55 & 25 & 22 & 2.2 & 2 & Medium \\
11 & 68 & 28 & 25 & 2.4 & 2 & Medium \\
12 & 58 & 25 & 23 & 2.3 & 2 & Medium \\
Mean \pm SD & $74.8 \pm 23.7$ & $29.5 \pm 9.2$ & $29.9 \pm 9.3$ & $2.6 \pm 0.4$ & & \\
\hline
\end{tabular}

avulsed humeral insertion site $(P=0.000)$. The ratio between these of $2.6 \pm 0.4$ (range 2.1-3.5) was defined as the repair ratio. There was a high correlation between the length of torn tendon edge and the amount of retraction $(r=0.94, P=0.000)$.

\section{Discussion}

To the best of our knowledge, this is the first quantitative study showing the discrepancy between the torn tendon edge and avulsed humeral insertion site in medium and large size rotator cuff tears. The length of the torn tendon edge was more than twice the size of the avulsed humeral insertion in medium and large size, retracted rotator cuff tears. This precludes simple tendon-to-bone apposition of the entire length of the torn tendon edge. Attempts to pull the torn tendon edge of a retracted tear to the bone of the avulsed humeral insertion may not minimize tension in the rotator cuff repair. Small tension has been prior shown to yield improved outcome after the rotator cuff repair compared to those with large tension [43, 44]. Undue tension of the repair can be confirmed by the surgeon being able to place the arm at the side [7] or in a functional position [8] at the completion of the repair.

Repair ratio was defined as the ratio of the length of the torn tendon edge and the length of the avulsed insertion site. It may be helpful in simultaneously assessing factors of retraction and size of rotator cuff tears, both known to affect outcome [8, 10, 45-49]. Greater retraction is associated with tears of increased size and also indicates there was more severe damage to the tendon. The length of torn tendon edge is highly correlated to the amount of retraction. Yet for two tears with the same amount of retraction, the one with a greater repair ratio, and therefore a smaller size of humeral avulsion site, may be the more difficult to repair.
In addition, both the length of the torn tendon edge and the length of the avulsed insertion site can be quantified and are independent of shoulder position. Retraction is dependent on shoulder position, being larger for a given size rotator cuff tear with the shoulder in adduction than abduction [50, 51].

Side-to-side repair can be used to close a longitudinal rotator cuff tear [52] but alone, it can not restore the anatomical relationship of the rotator cuff to the greater tuberosity during repair of a rotator cuff tear. It may, however, be used as part of the repair to enable better apposition of the repair to bone. Side-to-side repair of the torn tendon edge was described prior as "margin convergence" [12]. This concept was described as reducing the load necessary to pull the torn tendon edge to the bone of the avulsed insertion site. Retracted, U-shaped tears could be lessened in size and converted to crescent-shaped tears for repair to bone. Margin convergence may also minimize portions of torn tendon that gather between the sutures, commonly called "dog ears". The repair ratio provides a guide for application of margin convergence. Assuming that the muscle-tendon unit is resilient, if the repair ratio equals one, the entire length of the torn tendon edge can be repaired to the bone of the avulsed insertion site. If the repair ratio is two, then $50 \%$ of the torn tendon edge should be repaired to the bone of the avulsed insertion site. The remainder of the torn tendon edge that cannot be repaired to bone should be repaired with a side-to-side technique. If the repair ratio is three, such as was the case for some of the tears in the present study, then only one-third of the torn tendon edge should be repaired to the bone of the avulsed insertion site. In the current study, comprised of medium and large size rotator cuff tears, the repair ratio was always greater than two. This might imply that in medium to large size rotator cuff tears, only less than half of the torn tendon edge can be repaired back to avulsed insertion site. 
Study of a greater number of specimens may have yielded more specific guidelines for repair. This study is limited to the trapezoidal or U-shaped rotator cuff tears since some type of tears such as L-shaped are not represented. It may be challenging to perform the measurements in clinical setting and requires further study. Also mobilization and release of the rotator cuff tendon, known to be important component of repair of retracted rotator cuff tears was not assessed in these cadaveric shoulders. If the repair cannot be achieved without undue tension, release of the capsule and mobilization of the rotator cuff outside the joint can be done. Release at the rotator interval, coined the interval slide, can be also be used to mobilize the rotator cuff and minimize tension on the repair [8].

As only the length of the torn tendon edge equal to the length of the avulsed humeral insertion site can be repaired to bone, a repair ratio more than one precludes a simple repair. There is a discrepancy between the length of the torn tendon edge and the length of the avulsed humeral insertion site (i.e. repair ratio $>1$ ) in retracted, medium and large size rotator cuff tears. An additional repair technique such as margin convergence would be necessary for the remaining unapproximated torn tendon edge in these rotator cuff tears.

Open Access This article is distributed under the terms of the Creative Commons Attribution Noncommercial License which permits any noncommercial use, distribution, and reproduction in any medium, provided the original author(s) and source are credited.

\section{References}

1. Meislin RJ, Sperling JW, Stitik TP (2005) Persistent shoulder pain: epidemiology, pathophysiology, and diagnosis. Am J Orthop 34(12 suppl):5-9

2. Milgrom C, Schaffler M, Gilbert S, van Holsbeeck M (1995) Rotator-cuff changes in asymptomatic adults. The effect of age, hand dominance and gender. J Bone Joint Surg Br 77(2):296-298

3. Sher JS, Uribe JW, Posada A, Murphy BJ, Zlatkin MB (1995) Abnormal findings on magnetic resonance images of asymptomatic shoulders. J Bone Joint Surg Am 77(1):10-15

4. Yamaguchi K, Sher JS, Andersen WK, Garretson R, Uribe JW, Hechtman K, Neviaser RJ (2000) Glenohumeral motion in patients with rotator cuff tears: a comparison of asymptomatic and symptomatic shoulders. J Shoulder Elbow Surg 9(1):6-11. doi:10.1016/ S1058-2746(00)90002-8

5. Gartsman GM (1998) Combined arthroscopic and open treatment of tears of the rotator cuff. Instr Course Lect 47:51-57

6. Yamaguchi K (2001) Mini-open rotator cuff repair: an updated perspective. Instr Course Lect 50:53-61

7. Arroyo SJ, Flatow EL (1999) Management of rotator cuff disease: intact and repairable cuff. In: Ianotti JP, Williams GR (eds) Disorders of the shoulder: diagnosis and management. Lippincott Williams \& Wilkins, Philadelphia, pp 31-56

8. Bigliani LU, Cordsco FA, McIIveen SJ, Musso ES (1992) Operative treatment of massive cuff tears: long-term results. J Shoulder Elbow Surg 1:120-130

9. Cofield RH (1982) Subscapular muscle transposition for repair of chronic rotator cuff tears. Surg Gynecol Obstet 154(5):667-672
10. DeOrio JK, Cofield RH (1984) Results of a second attempt at surgical repair of a failed initial rotator-cuff repair. J Bone Joint Surg Am 66(4):563-567

11. Post M, Silver R, Singh M (1983) Rotator cuff tear. Diagnosis and treatment. Clin Orthop Relat Res (173):78-91

12. Burkhart SS, Athanasiou KA, Wirth MA (1996) Margin convergence: a method of reducing strain in massive rotator cuff tears. Arthroscopy 12(3):335-338. doi:10.1016/S0749-8063(96)90070-5

13. DePalma AF (1983) Disorders associated with biologic aging of the shoulder. In: DePalma AF (ed) The Shoulder, 3rd edn. JB Lippincott, Philadelphia, pp 242-298

14. Ellman H (1993) Rotator cuff disorders. In: Ellman H, Gartsman GM (eds) Arthroscopic shoulder surgery and related procedures. Lea \& Febiger, Philadelphia, pp 98-119

15. Harryman DT 2nd, Mack LA, Wang KY, Jackins SE, Richardson ML, Matsen FA 3rd (1991) Repairs of the rotator cuff. Correlation of functional results with integrity of the cuff. J Bone Joint Surg Am 73(7):982-989

16. Neer CSI (1990) Cuff tears, biceps lesions, and impingement. In: Neer CSI (ed) Shoulder reconstruction. WB Saunders, Philadelphia, pp 63-70

17. Ellman H (1991) Surgical treatment of rotator cuff rupture. In: Watson M (ed) Surgical disorders of the shoulders. Churchill Livingstone, New York, pp 283-294

18. Gerber C, Vinh TS, Hertel R, Hess CW (1988) Latissimus dorsi transfer for the treatment of massive tears of the rotator cuff. A preliminary report. Clin Orthop Relat Res (232):51-61

19. Baker CL, Liu SH (1995) Comparison of open and arthroscopically assisted rotator cuff repairs. Am J Sports Med 23(1):99-104. doi: $10.1177 / 036354659502300117$

20. Blevins FT, Warren RF, Cavo C, Altchek DW, Dines D, Palletta G, Wickiewicz TL (1996) Arthroscopic assisted rotator cuff repair: results using a mini-open deltoid splitting approach. Arthroscopy 12(1):50-59. doi:10.1016/S0749-8063(96)90219-4

21. Burkhart SS, Danaceau SM, Pearce CE Jr (2001) Arthroscopic rotator cuff repair: analysis of results by tear size and by repair technique-margin convergence versus direct tendon-to-bone repair. Arthroscopy 17(9):905-912. doi:10.1053/jars.2001.26821

22. Djurasovic M, Marra G, Arroyo JS, Pollock RG, Flatow EL, Bigliani LU (2001) Revision rotator cuff repair: factors influencing results. J Bone Joint Surg Am 83A(12):1849-1855

23. Ellman H, Kay SP, Wirth M (1993) Arthroscopic treatment of fullthickness rotator cuff tears: 2- to 7-year follow-up study. Arthroscopy 9(2):195-200. doi:10.1016/S0749-8063(05)80374-3

24. Grondel RJ, Savoie FH 3rd, Field LD (2001) Rotator cuff repairs in patients 62 years of age or older. J Shoulder Elbow Surg 10(2):97-99. doi:10.1067/mse.2001.110513

25. Hata Y, Saitoh S, Murakami N, Seki H, Kobayashi H, Takaoka K (2001) Shrinkage in the inferior pouch of the scapulohumeral joint is related to postoperative pain after rotator cuff repair: radiographic and arthrographic comparison between patients with postoperative pain and those without it. J Shoulder Elbow Surg 10(4):333-339. doi:10.1067/mse.2001.115366

26. Hawkins RJ, Misamore GW, Hobeika PE (1985) Surgery for fullthickness rotator-cuff tears. J Bone Joint Surg Am 67(9):13491355

27. Jost B, Pfirrmann CW, Gerber C, Switzerland Z (2000) Clinical outcome after structural failure of rotator cuff repairs. J Bone Joint Surg Am 82(3):304-314

28. Pai VS, Lawson DA (2001) Rotator cuff repair in a district hospital setting: outcomes and analysis of prognostic factors. J Shoulder Elbow Surg 10(3):236-241. doi:10.1067/mse.2001.113963

29. Posada A, Uribe JW, Hechtman KS, Tjin ATEW, Zvijac JE (2000) Mini-deltoid splitting rotator cuff repair: do results deteriorate with time? Arthroscopy 16(2):137-141. doi:10.1016/S0749-8063(00) 90026-4 
30. Rokito AS, Zuckerman JD, Gallagher MA, Cuomo F (1996) Strength after surgical repair of the rotator cuff. J Shoulder Elbow Surg 5(1):12-17. doi:10.1016/S1058-2746(96)80025-5

31. Shinners TJ, Noordsij PG, Orwin JF (2002) Arthroscopically assisted mini-open rotator cuff repair. Arthroscopy 18(1):21-26. doi:10.1053/jars.2002.26480

32. Warner JJ, Higgins L, Parsons IMt, Dowdy P (2001) Diagnosis and treatment of anterosuperior rotator cuff tears. J Shoulder Elbow Surg 10(1):37-46. doi:10.1067/mse.2001.112022

33. Yel M, Shankwiler JA, Noonan JE Jr, Burkhead WZ Jr (2001) Results of decompression and rotator cuff repair in patients 65 years old and older: 6- to 14-year follow-up. Am J Orthop 30(4):347-352

34. Bigliani LU, Cordasco FA, McIlveen SJ, Musso ES (1992) Operative treatment of failed repairs of the rotator cuff. J Bone Joint Surg Am 74(10):1505-1515

35. Cofield RH (1985) Rotator cuff disease of the shoulder. J Bone Joint Surg Am 67(6):974-979

36. Cordasco FA, Bigliani LU (1997) The rotator cuff. Large and massive tears. Technique of open repair. Orthop Clin North Am 28(2):179-193. doi:10.1016/S0030-5898(05)70278-9

37. Melillo AS, Savoie FH 3rd, Field LD (1997) Massive rotator cuff tears: debridement versus repair. Orthop Clin North Am 28(1):117-124. doi:10.1016/S0030-5898(05)70269-8

38. Montgomery TJ, Yerger B, Savoie FH (1994) Management of rotator cuff tears: a comparison of arthroscopic debridement and surgical repair. J Shoulder Elbow Surg 3:71-78

39. Bateman JE (1963) The diagnosis and treatment of ruptures of the rotator cuff. Surg Clin North Am 43:1523-1530

40. Neviaser JS, Neviaser RJ, Neviaser TJ (1978) The repair of chronic massive ruptures of the rotator cuff of the shoulder by use of a freeze-dried rotator cuff. J Bone Joint Surg Am 60(5):681-684

41. Ozaki J, Fujimoto S, Masuhara K, Tamai S, Yoshimoto S (1986) Reconstruction of chronic massive rotator cuff tears with synthetic materials. Clin Orthop Relat Res (202):173-183
42. Ha'eri GB, Wiley AM (1981) Advancement of the supraspinatus muscle in the repair of ruptures of the rotator cuff. J Bone Joint Surg Am 63(2):232-238

43. Davidson PA, Rivenburgh DW (2000) Rotator cuff repair tension as a determinant of functional outcome. J Shoulder Elbow Surg 9(6):502-506. doi:10.1067/mse.2000.109385

44. Hersche O, Gerber C (1998) Passive tension in the supraspinatus musculotendinous unit after long-standing rupture of its tendon: a preliminary report. J Shoulder Elbow Surg 7(4):393-396. doi:10.1016/S1058-2746(98)90030-1

45. Bjorkenheim JM, Paavolainen P, Ahovuo J, Slatis P (1988) Surgical repair of the rotator cuff and surrounding tissues. Factors influencing the results. Clin Orthop Relat Res (236):148-153

46. Cofield RH, Hoffmeyer P, Lanzar WH (1990) Surgical repair of chronic rotator cuff tears. Orthop Trans 14:251-252

47. Gore DR, Murray MP, Sepic SB, Gardner GM (1986) Shoulder-muscle strength and range of motion following surgical repair of fullthickness rotator-cuff tears. J Bone Joint Surg Am 68(2):266-272

48. Iannotti JP, Bernot MP, Kuhlman JR, Kelley MJ, Williams GR (1996) Postoperative assessment of shoulder function: a prospective study of full-thickness rotator cuff tears. J Shoulder Elbow Surg 5(6):449-457. doi:10.1016/S1058-2746(96)80017-6

49. Pollock RG, Black ADEBS, EB S, Flatow EL, Bigliani LU (1996) Surgical management of rotator cuff disease. J Shoulder Elbow Surg 5:S37. doi:10.1016/S1058-2746(96)80197-2

50. Hatakeyama Y, Itoi E, Pradhan RL, Urayama M, Sato K (2001) Effect of arm elevation and rotation on the strain in the repaired rotator cuff tendon. A cadaveric study. Am J Sports Med 29(6):788-794

51. Zuckerman JD, Leblanc JM, Choueka J, Kummer F (1991) The effect of arm position and capsular release on rotator cuff repair. A biomechanical study. J Bone Joint Surg Br 73(3):402-405

52. McLaughlin HL (1944) Lesions of the musculotendinous cuff of the shoulder: the exposure and treatment of tears with retraction. $\mathrm{J}$ Bone Joint Surg Am 26:31-51 